\title{
Influence of oil film stiffness on natural characteristics of single-rotor three-input helicopter main gearbox
}

\author{
Yuan Chen ${ }^{1}$, Ru Peng Zhu' ${ }^{2}$ Zai Chun Feng ${ }^{3}$, Guang Hu Jin ${ }^{4}$, Wei Zhang ${ }^{5}$ \\ ${ }_{1,2,4,5}$ College of Mechanical and Electrical Engineering, Nanjing University of Aeronautics and \\ Astronautics, Nanjing, 210016, China \\ ${ }^{3}$ Department of Mechanical and Aerospace Engineering, University of Missouri, Columbia, USA \\ ${ }^{2}$ Corresponding author

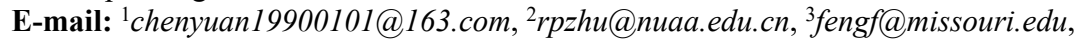 \\ 4meeghjin@nuaa.edu.cn, ${ }^{5}$ zwsmile12@163.com
}

Received 29 January 2018; accepted 5 February 2018

DOI https://doi.org/10.21595/vp.2018.19707

Check for updates

\begin{abstract}
The elastohydrodynamic lubrication (EHL) contact model is established, the oil film stiffness is calculated based on Dowson-Higginson empirical minimum thickness equation. The vibration model of single-rotor three-input helicopter main reducer is proposed by lumped mass method, and nonlinear factors like oil film stiffness, dynamic meshing force are taken into account. The influence of oil film stiffness on system natural frequency is analyzed as well. The results show that oil film stiffness of the internal and external meshing pairs in the planetary gear system have greater impact on the natural frequency, which tends to destabilize the system. Therefore, the planetary gear train is the most crucial branch regarding the system splash lubrication. When all the oil film stiffness in the system are greater than $4 \times 10^{9} \mathrm{~N} / \mathrm{m}$, the natural frequencies tend to be stable. This study can provide the theoretical reference for the lubrication characteristics in the single-rotor multi-input helicopter.
\end{abstract}

Keywords: helicopter main reducer, natural characteristics, oil film stiffness, nonlinear dynamics.

\section{Introduction}

To protect the tooth surface, the gears normally work in the lubrication condition. With load and entrainment velocity, the lubricating oil forms a certain film thickness on the contact surface of the gear pair. When working condition changes, the film follows with deformation, the oil film stiffness changes. Study of the influence law of the oil film stiffness on the natural characteristics has important engineering significance.

Within the scope of the multi-stage helicopter main reducer, especially regarding natural frequency analysis. Kahraman [1] applied eigenvalue solution and the modal summation technique to predict the free and forced vibrations of the multi-stage gear transmission system. Huang [2] established a finite element model of a parallel three-shaft gear-rotor coupling system and analyzed the influences of the mesh stiffness, the installation angle, the helix angle and the bearing stiffness on the natural characteristics. Choy [3] analyzed the modal characteristics by using the matrix-transfer technique. Chen [4] studied the influence of torsional stiffness on natural characteristics of four-stage main transmission system in three-engine helicopter. Li [5] investigated the damping mechanism and EHL characteristics at the interface of the two DOF spur gear pair.

In summary, at present, the influence of oil film stiffness on the multi-stage system natural characteristics, is not to be investigated, according to the limited published issues. Therefore, it is of great theoretical significance and engineering value to study the mechanism of oil film stiffness on vibration and noise in gear transmission.

\section{System dynamic model}

\subsection{Dynamic modeling}

The dynamic model of single-rotor three-input helicopter main reducer is shown in Fig. 1 [6]. 
The system includes three input branches, a tail output branch and a planet train branch. $\theta_{1}^{(j)}, \theta_{2}^{(j)}$, $\theta_{3}^{(j)}, \theta_{4}^{(j)}, \theta_{5}^{(j)}, \theta_{6}, \theta_{c}, \theta_{7}, \theta_{8}, \theta_{9}, \theta_{s}$ and $\theta_{p i}$ are rotational DOF of gear system in each stage. $k_{i n}$, $k_{23}, k_{45}, k_{78}, k_{\text {out }}$ and $k_{6 s}$ are torsional stiffness of shafts connecting each gear pair; $c_{12}, c_{34}, c_{56}$, $c_{s p i}$ and $c_{r p i}$ are meshing damping of each gear pair; $k_{12}, k_{34}, k_{56}, k_{s p i}$ and $k_{r p i}$ are meshing stiffness of each gear pair; $k_{m}$ represents oil film stiffness.

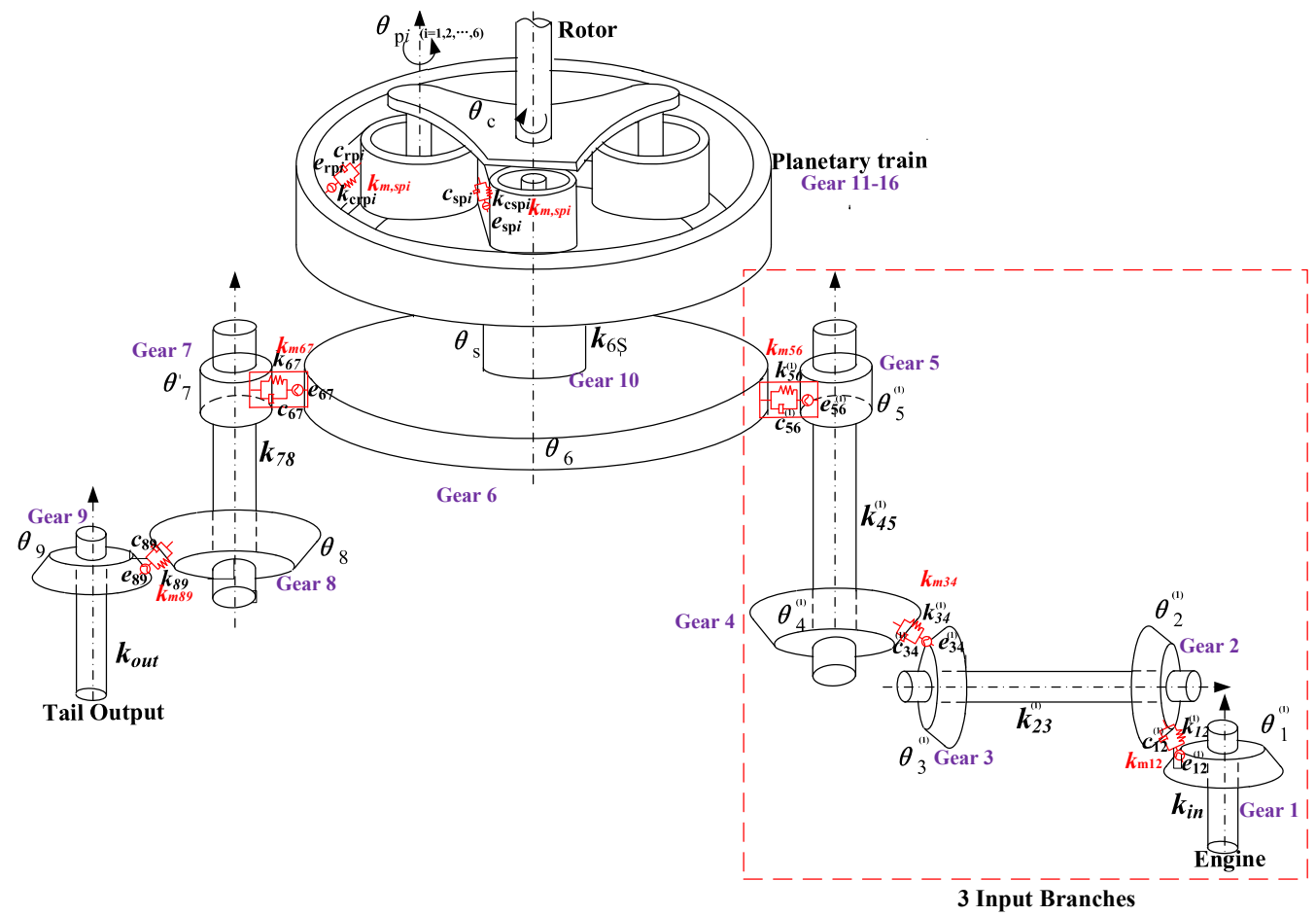

Fig. 1. Dynamic model of single-rotor three-input helicopter main reducer

\subsection{Differential equation}

For the EHL model, Dowson achieved a large amount of data through numerical simulation and experimental measurements and proposed the empirical equation for calculating the minimum oil film thickness. The Dowson-Higginson minimum oil film thickness empirical equation is [7]:

$h_{m}=2.65 U^{0.7} G^{0.54} W^{-0.13} R$,

where $U, G, W$ are dimensionless speed, material, load respectively:

$U=\frac{\eta_{0} u_{r}}{E^{\prime} R}, \quad G=\alpha_{l} E^{\prime}, \quad W=\frac{F}{E^{\prime} R}, \quad \frac{2}{E^{\prime}}=\frac{1-v_{1}^{2}}{E_{1}}+\frac{1-v_{2}^{2}}{E_{2}}$,

where, $F$ is the load in meshing line, $E^{\prime}$ is the equivalent elastic modulus, $R$ is synthetical curvature radius, $u_{r}$ is entrainment velocity, $\alpha_{l}$ is pressure-viscosity coefficient, $\eta_{0}$ is dynamic viscosity. $E_{1}, E_{2}$ and $v_{1}, v_{2}$ are the contact elastic modulus and Poisson's ratio.

The minimum oil film stiffness based on Dowson-Higginson oil film thickness can be derived by taking the derivative of Eq. (1):

$$
k_{h m}=7.69 B E^{\prime} R\left(2.65 U^{0.7} G^{0.54} R\right)^{7.69} h_{m}^{-8.69},
$$


here, $B$ is contact length.

Time-varying meshing stiffness can be expanded in the Fourier series with the fundamental meshing frequency:

$$
\left\{\begin{array}{l}
k_{12}^{(j)}(t)=k_{m 12}+k_{a 12} \sin \left(\omega_{12} t+\beta_{12}\right), \\
k_{34}^{(j)}(t)=k_{m 34}+k_{a 34} \sin \left(\omega_{34} t+\beta_{34}\right), \\
k_{56}^{(j)}(t)=k_{m 56}+k_{a 56} \sin \left(\omega_{56} t+\beta_{56}\right), \\
k_{67}(t)=k_{m 67}+k_{a 67} \sin \left(\omega_{67} t+\beta_{67}\right), \\
k_{89}(t)=k_{m 89}+k_{a 89} \sin \left(\omega_{89} t+\beta_{89}\right), \\
k_{s p i}(t)=k_{m, s p i}+k_{a, s p i} \sin \left(\omega t+\beta_{s p i}\right), \\
k_{r p i}(t)=k_{m, r p i}+k_{a, r p i} \sin \left(\omega t+\beta_{r p i}\right),
\end{array}\right.
$$

where $k_{12}^{(j)}(t), k_{34}^{(j)}(t), k_{56}^{(j)}(t), k_{67}(t), k_{89}(t), k_{s p i}(t)$ and $k_{r p i}(t)$ are time-varying mesh stiffness in each gear pair. $k_{m}$ is average meshing stiffness considering oil film stiffness, $k_{a}$ is maximum variable meshing stiffness. $\beta$ is initial meshing phase.

The differential equation of the single-rotor multi-input helicopter main reducer can be deduced through Newton's law, as shown in Eq. (4):

$$
\begin{aligned}
& \left(J_{1} \ddot{\theta}_{1}^{(j)}+\left[F_{12}^{p(j)}(t)+F_{12}^{d(j)}(t)\right] r_{1}+k_{i n} \theta_{1}^{(j)}=T_{E j},\right. \\
& J_{2} \ddot{\theta}_{2}^{(j)}-\left[F_{12}^{p(j)}(t)+F_{12}^{d(j)}(t)\right] r_{2}+k_{23}^{(j)}\left(\theta_{2}^{(j)}-\theta_{3}^{(j)}\right)=0 \text {, } \\
& J_{3} \ddot{\theta}_{3}^{(j)}+\left[F_{34}^{p(j)}(t)+F_{34}^{d(j)}(t)\right] r_{3}+k_{23}^{(j)}\left(\theta_{3}^{(j)}-\theta_{2}^{(j)}\right)=0 \text {, } \\
& J_{4} \ddot{\theta}_{4}^{(j)}-\left[F_{34}^{p(j)}(t)+F_{34}^{d(j)}(t)\right] r_{4}+k_{45}^{(j)}\left(\theta_{4}^{(j)}-\theta_{5}^{(j)}\right)=0, \\
& J_{5} \ddot{\theta}_{5}^{(j)}+\left[F_{56}^{p(j)}(t)+F_{56}^{d(j)}(t)\right] r_{5}+k_{45}^{(j)}\left(\theta_{5}^{(j)}-\theta_{4}^{(j)}\right)=0, \\
& J_{6} \ddot{\theta}_{6}-\sum_{j=1}^{3}\left[F_{56}^{p(j)}(t)+F_{56}^{d(j)}(t)\right] r_{6}+\left[F_{67}^{p(j)}(t)+F_{67}^{d(j)}(t)\right] r_{6}+k_{6 s}\left(\theta_{6}-\theta_{s}\right)=0 \text {, } \\
& \left\{J_{7} \ddot{\theta}_{7}-\left[F_{67}^{p(j)}(t)+F_{67}^{d(j)}(t)\right] r_{7}+k_{78}\left(\theta_{7}-\theta_{8}\right)=0\right. \text {, } \\
& J_{8} \ddot{\theta}_{8}+\left[F_{89}^{p(j)}(t)+F_{89}^{d(j)}(t)\right] r_{8}+k_{78}\left(\theta_{8}-\theta_{7}\right)=0 \text {, } \\
& J_{9} \ddot{\theta}_{9}-\left[F_{89}^{p(j)}(t)+F_{89}^{d(j)}(t)\right] r_{9}+k_{R R} \theta_{9}=-T_{R R} \text {, } \\
& J_{s} \ddot{\theta}_{s}+\sum_{i=1}^{N}\left[F_{s p i}^{p}(t)+F_{s p i}^{d}(t)\right] r_{s}-k_{6 s}\left(\theta_{6}-\theta_{s}\right)=0, \\
& J_{p} \ddot{\theta}_{p i}-\left[F_{s p i}^{p}(t)+F_{s p i}^{d}(t)\right] r_{p}+\left[F_{r p i}^{p}(t)+F_{r p i}^{d}(t)\right] r_{p}=0, \\
& {\left[J_{c}+\sum_{i=1}^{N}\left(m_{p i} r_{c}^{2}\right)\right] \ddot{\theta}_{c}-\sum_{i=1}^{N}\left[F_{s p i}^{p}(t)+F_{s p i}^{d}(t)+F_{r p i}^{p}(t)+F_{r p i}^{d}(t)\right] r_{c} \cos \alpha=-T_{M R} \text {, }}
\end{aligned}
$$

where $T_{E j}$ is the torque of engine $j(j=1,2,3) ; T_{R R}$ and $T_{M R}$ are the torque of tail branch and planet carrier. $F^{p}$ and $F^{d}$ are dynamic meshing and damping forces. $J_{c}$ is carrier moment of inertia.

In addition, after the decomposition and recombination of Eq. (4), it can be expressed with mass matrix, damping matrix and stiffness matrix form. By setting the value of damping item and external excitation item to be zero, the vibration differential equation of the system under free condition can be obtained. 


\section{System natural characteristics analysis}

Gear parameters are listed in Table 1, and EHL parameters are shown in Table 2.

Table 1. Gear parameters

\begin{tabular}{|c|c|c|c|}
\hline Gear & Tooth number & Module & Face width $(\mathrm{mm})$ \\
\hline Gear 1 & 30 & 4.5 & 40 \\
\hline Gear 2 & 85 & 4.5 & 40 \\
\hline Gear 3 & 40 & 5 & 45 \\
\hline Gear 4 & 90 & 5 & 45 \\
\hline Gear 5 & 25 & 4.75 & 40 \\
\hline Gear 6 & 142 & 4.75 & 40 \\
\hline Gear 7 & 40 & 5 & 40 \\
\hline Gear 8 & 60 & 5 & 35 \\
\hline Gear 9 & 70 & 5 & 35 \\
\hline Gear 10 & 68 & 5 & 28 \\
\hline Gear 11-16 & 37 & 5 & 28 \\
\hline
\end{tabular}

Table 2. EHL parameters

\begin{tabular}{|l|c|}
\hline \multicolumn{1}{|c|}{ Parameter } & Value \\
\hline Dynamic viscosity $\eta_{0}(\mathrm{~Pa} \cdot \mathrm{s})$ & 0.04 \\
\hline Pressure-viscosity coefficient $\alpha_{l}\left(\mathrm{~Pa}^{-1}\right)$ & $2.2 \times 10^{-8}$ \\
\hline Elastic modulus $E_{1}(\mathrm{~Pa})$ & $2 \times 10^{11}$ \\
\hline Elastic modulus $E_{2}(\mathrm{~Pa})$ & $2 \times 10^{11}$ \\
\hline Poisson's ratio $v_{1}$ & 0.3 \\
\hline Poisson's ratio $v_{2}$ & 0.3 \\
\hline
\end{tabular}

In order to explore the influence law of oil film stiffness on natural characteristics of the system, the natural frequencies of the first five orders are calculated and depicted in Fig. 2. Fig. 2(a) and Fig. 2(b) are the influence of oil film stiffness on natural frequency in first stage and the second stage, as shown in the figure, when the oil film stiffness is greater than $2 \times 10^{9} \mathrm{~N} / \mathrm{m}$, the natural frequencies no longer change. When the oil film stiffness is less than $2 \times 10^{9} \mathrm{~N} / \mathrm{m}$, the decrease of natural frequency of the fourth and fifth order is the most obvious. Fig. 2(c) shows the effect of oil film stiffness on the natural frequency in the third stage. The figure shows that when $k_{56}$ is less than $2 \times 10^{9} \mathrm{~N} / \mathrm{m}$, the first-order natural frequency decreases rapidly. Fig. 2(d) and Fig. 2(e) show the impact of oil film stiffness on natural frequency in the tail branch. When $k_{67}$ is less than $4 \times 10^{9} \mathrm{~N} / \mathrm{m}$, the first-order natural frequency decreases sharply; when $k_{89}$ is less than $0.5 \times 10^{9} \mathrm{~N} / \mathrm{m}$, the natural frequency of the fifth order decreases while the natural frequencies of other orders do not change. Fig. 2(f) and Fig. 2(g) are the influence law of planetary gear train on the system natural frequency, as seen from the figure, when the internal and external meshing oil film stiffness are equal to $0.7 \times 10^{9} \mathrm{~N} / \mathrm{m}$ and $0.9 \times 10^{9} \mathrm{~N} / \mathrm{m}$, the natural frequency of each order has a sudden drop-point, which could easily destabilize the system. Therefore, the planetary gear train is the most important branch in splash lubrication analysis, the oil film stiffness cannot be too small in mechanical design.

\section{Conclusions}

In this paper, a dynamic model of single-rotor three-input helicopter main reducer is proposed and influence laws of the oil film stiffness are calculated, the analysis results enable us to draw the following conclusions:

1) The influence laws of the oil film stiffness of the two gear pairs in the input branch are almost the same, the influence laws of the internal and external meshing pairs in the planetary gear system are also very similar, therefore these two branches should consider all components within the branch. 


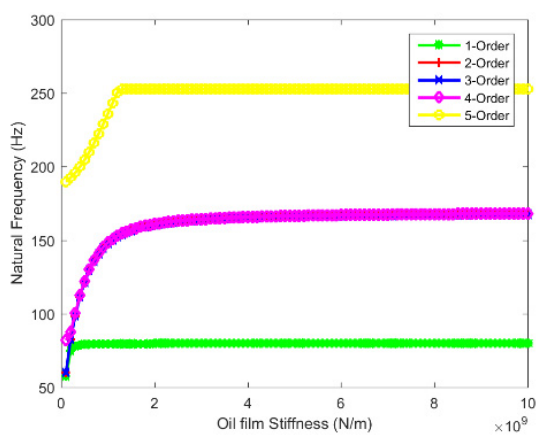

a) $k_{12}$

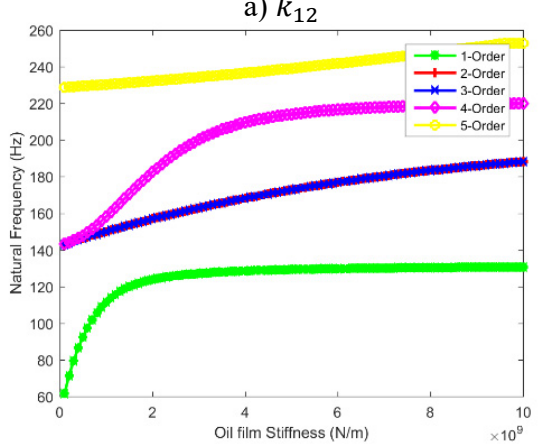

c) $k_{56}$

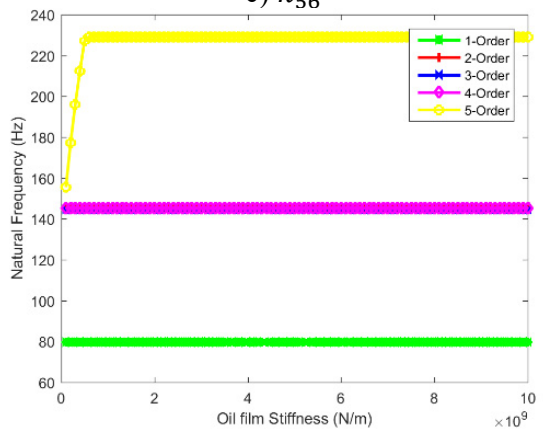

e) $k_{89}$

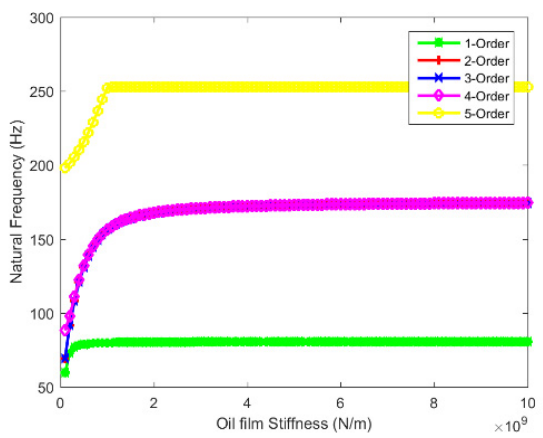

b) $k_{34}$

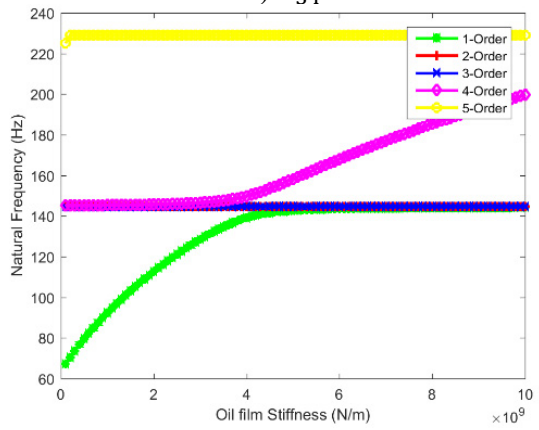

d) $k_{67}$

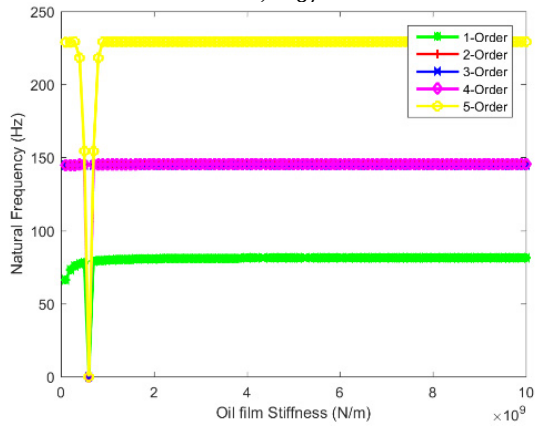

f) $k_{m s p}$

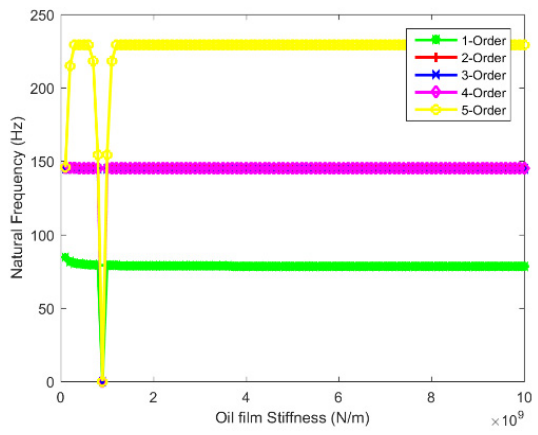

g) $k_{m r p}$

Fig. 2. Impact of oil film stiffness on first five orders natural frequency

2) When the oil film stiffness is small, the natural frequencies of each order can be variable. When the oil films stiffness of all meshing pairs in the system is more than $4 \times 10^{9} \mathrm{~N} / \mathrm{m}$, the natural frequencies tend to be stable.

3) Planetary gear train is the most critical branch of the single-rotor three-input system 
regarding splash lubrication, so their oil film stiffness cannot be too small during working condition.

\section{Acknowledgements}

This work is supported by the National Natural Science Foundation of PRC (Grant No. 51775265 and 51475226); China Scholarship Council; China Association for Science and Technology.

\section{References}

[1] Kahraman A., Zini D. M., Kienzle K. Dynamic analysis of a multi-shaft helical gear transmission by finite elements: model and experiment. ASME Journal of Vibrations and Acoustics, Vol. 126, Issue 3, 2004, p. 398-406.

[2] Huang J., Zhang S., Zhang Y. The influences of system parameters on the natural characteristics of a parallel multi-shaft gear-rotor system. Machinery Design and Manufacture, Vol. 7, 2013, p. 15-17, (in Chinese).

[3] Choy F. K., Ruan Y. F., R. K., Zakrajsek J. J., Townsend D. P. Modal analysis of multistage gear systems coupled with gearbox vibrations. Journal of Mechanical Design, Vol. 114, Issue 3, 2008, p. $486-497$.

[4] Chen Y., Zhu, R. P., Xiong, Jin, G. H. Analysis on natural characteristics of four-stage main transmission system in three-engine helicopter. Vibroengineering Procedia, Vol. 12, 2017, p. 19-23.

[5] Li S., Kahraman A. A spur gear mesh interface damping model based on elastohydrodynamic contact behaviour. International Journal of Powertrains, Vol. 1, Issue 1, 2011, p. 4-21.

[6] Bianchi A., Rossi S. Modeling and finite element analysis of a complex helicopter transmission including housing, shafts and gears. 1997, http://hdl.handle.net/20.500.11881/3273.

[7] Ye Y. D., Zhou Z. B. Research on influence of gear parameters on lubrication oil film thickness under condition of elasto hydrodynamic lubrication. Journal of Machine Design, Vol. 29, 9, p. 73-76, (in Chinese). 